\title{
Caracterización del limbo de Piper aduncum L. (Piperaceae): Análisis estructurales, histoquímicos y de sus aceites esenciales
}

\author{
Description of the limbo of Piper aduncum L. (Piperaceae): Structural analysis, \\ histochemical and essential oils
}

\author{
Sara Dousseau ${ }^{1 *}$, Izabel de Souza Chaves ${ }^{2}$, Evaristo Mauro de Castro², Amauri Alves de Alvarenga ${ }^{2}$, \\ Eduardo Alves ${ }^{3}$, José Eduardo Brasil Pereira Pinto², Jessé Marques da Silva Junior² \& Vanessa \\ Bastos PEREIRA ${ }^{2}$
}

\begin{abstract}
${ }^{1}$ Instituto Capixaba de Búsqueda, Asistencia Técnica y Extensión. Centro Regional para el Desarrollo Rural. Carretera BR-101 Norte, Km 151, Bebedouro, PO Box: 62, CEP 29915-140, Linhares-ES, Brasil.

${ }^{2}$ Sector de Fisiología Vegetal, Departamento de Biología, Universidad Federal de Lavras, Campus Universitario, PO Box 3037, CEP 37200-000, Lavras - MG, Brasil.

${ }^{3}$ Laboratorio de Microscopía Electrónica, Departamento de Fitopatología, Universidad Federal de Lavras, Campus Universitario, PO Box 3037, CEP 37200-000, Lavras - MG, Brasil.

*saradousseau@yahoo.com.br
\end{abstract}

\begin{abstract}
RESUMEN
Piper aduncum L. (Piperaceae) es una especie arbustiva umbrófila que se encuentra generalmente en suelos con elevado contenido de materia orgánica y humedad. De las hojas se extrae aceite esencial con acción insecticida, fungicida y bactericida, con una amplia utilización en el sector agrario y medicinal. El objetivo del trabajo fue caracterizar el limbo de $P$. aduncum. Se efectuó la caracterización anatómica e histoquímica de la sección transversal y la caracterización anatómica de la sección paradérmica apical, mediana y basal del limbo. Para ello las hojas fueron preparadas con las técnicas tradicionales de microscopía de luz y microscopía electrónica. El mesófilo es dorsiventral con capas subcelulares en ambas epidermis. En la epidermis y las capas subcelulares sólo se encontró la presencia de proteínas totales. En el parénquima en empalizada y en el parénquima esponjoso fueron observados almidón, lípidos totales e insaturados. En el parénquima fundamental fueron encontrados almidón, proteína, lípidos totales, ortodihidroxifenoles y terpenoides con grupo carbonilo. Están presentes idioblastos unicelulares en las capas subcelulares de la epidermis del mesófilo hipoestomático, los estomas son tetracíticos y salientes. En los idioblastos oleíferos fue detectada la presencia de lípidos totales, ortodihidroxifenoles, lactonas sesquiterpénicas y terpenoides con grupo carbonilo. Fueron observados tricomas tectores unicelulares cortos, de extremos agudos, pluricelulares de extremos agudos y capitados, y tricomas glandulares saculares y glándulas perladas. En la porción basal de los tricomas tectores fueron encontradas proteínas totales y en los tricomas saculares, proteína, lípidos totales y ortodihidroxifenoles.
\end{abstract}

Palabras clave: Anatomía, Piperaceae, variabilidad morfológica.

\begin{abstract}
Piper aduncum L. is a shrub specie, found mainly in soil with elevated organic matter and humidity. The essential oil containing insecticide and bactericide action, and also has broad application in agricultural and medicinal areas. The objective of this study is to characterize the lamina of $P$. aduncum. There was realized anatomical and histochemical characterization of paradermic, and anatomical characterization of transversal sections from apical region, median and basal of leaf blade, prepared according to usual technique of light and electronic microscopy of scaning. The mesophyll is dorsiventral with subcelular layer in both epiderms. In the epidermis and subcelular layers, it was only found the presence of total protein. In the palisade and spongyous parenchyma were found starch total and insaturated lipids. In the fundamental parenchyma there were visualized starch, protein, total lipids, ortodihidroxiphenols and terpenoid with carbonil group. There are present unicellular idioblasts in subcelular layers, epiderm or mesophyll. It is hipoestomatic, contains tetracitic stomates. There were observed short trichome tector unicellular with fine cap, pluricelular with fine cap and glandular saclike trichome and perolated glandula. In the basal portion of the tector trichomes there were found total protein. In the oil idioblast there were observed the presence of total lipids, ortodihidroxiphenols, sesquiterpenic lactones and terpenoid with carbonil group, while it was possible to observe in the sac-like trichomes, protein, total lipids and ortodihidroxiphenols.
\end{abstract}

KEYwORDS: Anatomy, Piperaceae, morphological variability. 


\section{INTRODUCCIÓN}

Piper aduncum L. (Piperaceae) es conocido popularmente como falso-jaborandi, aperta-ruão y cordoncillo, es un arbusto con propiedades medicinales nativo de América tropical y ampliamente distribuida en casi todo el territorio brasileño. Es una planta umbrófila, encontrada en varias estructuras boscosas, especialmente en suelos con elevado contenido de materia orgánica y humedad (Lorenzi \& Matos 2002).

De sus hojas se extrae alto contenido de aceite esencial $(1,8-2,2 \%)$, el cual es utilizado en la agricultura debido a su acción insecticida (Fazolin et al. 2005, Estrela et al. 2006, Fazolin et al. 2007) y fungicida (Bastos \& Albuquerque 2004, Navickiene et al. 2006). Además es utilizado en tratamiento contra microorganismos patógenos al ser humano (Fidalgo et al. 2004, Duarte et al. 2005).

El conocimiento de las características anatómicas e histoquímicas de los órganos responsables por la síntesis y almacenamiento de los principios activos de las plantas, es de fundamental importancia en las decisiones agronómicas, auxiliando la planificación de estrategias específicas para el manejo postcosecha de los cultivos de las plantas medicinales (Reis \& Mariot 2001). En cuanto al aspecto estructural del limbo, su descripción posibilita la identificación de especies de interés en su estado vegetativo, especialmente en aquellos locales donde se encuentran otras especies del mismo género.

$\mathrm{La}$ características morfológicas y anatómicas de las especies del género Piper han sido ampliamente estudiadas en $P$. diospyrifolium Kunth (Souza et al. 2004), P. crassinervium Kunth (Albiero et al. 2005a), $P$. gaudichaudianum Kuntze (Albiero et al. 2005b) y $P$. hispidum Sw. (Albiero et al. 2006). Se sabe que la presencia de células secretoras de aceite es común en especies de Piperaceae (Metcalfe \& Chalk 1957, Barroso et al. 1978), i. e. en el parénquima, colénquima, tejido vascular del pecíolo y de la vena central y mesófilo o células subepidérmicas de Peperomia dahlstedtii, Ottonia martiana y Piper diospyrifolium (Souza et al. 2004). Sin embargo, para $P$. aduncum se encontró la referencia de Vianna \& Akisue (1997), sin información sobre la caracterización anatómica de la especie, utilizando microscopía electrónica de barrido. Hasta el momento no se han reportado referencias sobre la realización de pruebas histoquímicas para estas especies, aún no hay estudios que involucran la identificación de los aceites esenciales que se encuentran en las especies del género Piper (Parmar et al. 1997), incluyendo P. aduncum (Maia et al. 1998).

El objetivo de este estudio era caracterizar estructuralmente el limbo de $P$. aduncum, mostrando caracteres de mayor importancia para su identificación. La información de las estructuras obtenidas en este estudio puede complementar la caracterización eco-fisiológica de la especie y ofrecer elementos para la identificación macro y microscópica de compuestos fitoterapéuticos producidos a partir de ese órgano vegetal. Además, los resultados de las pruebas histoquímicas pueden servir como elementos de comparación cualitativa en la identificación de medicamentos fitoterapéuticos y en la prospección de los principios activos vegetales que produce la planta (Fank-deCarvalho \& Graciano-Ribeiro 2005).

\section{MATERIALES Y MÉTODOS}

Tres ramas plagiotrópicas fueron recolectadas en el Campus de la Universidad Federal de Lavras, identificados taxonómicamente y depositadas en el Herbario de la Universidad Federal de Lavras, con el número de registro 20275.

Después de la identificación taxonómica, un par de hojas completamente desarrolladas, localizadas en el tercer nudo a partir de la yema apical de las ramas plagiotrópicas, fueron recolectadas de cinco especímenes de Piper aduncum, para un total de diez hojas por tratamiento.

\section{CARACTERIZACIÓN ESTRUCTURAL}

Para la caracterización anatómica de la especie se utilizó microscopía de luz y las estructuras utilizadas fueron fijadas en etanol al $70 \%$. Se analizó la sección transversal del limbo de la hoja, los cortes de esta sección se realizaron con bisturí y luego fueron clareados con hipoclorito de sodio comercial diluido al 50\%, después lavadas con agua destilada, teñidas con safrablal (safranina y azul de Astra, 1:1), y nuevamente lavadas en agua destilada (Bukatsch 1972). Las secciones paradérmicas se obtuvieron por la disociación química de las epidermis adaxial y abaxial, sumergiéndolas en fragmentos de $1 \mathrm{~cm}^{2}$ en una mezcla de Jeffrey (ácido nítrico y ácido crómico al 10\%, 1:1), durante 12 h (Johansen 1940). La epidermis adaxial fue clareada en hipoclorito de sodio comercial diluido al $50 \%$, seguido de un lavado en agua destilada, teñida con safranina $1 \%$ y lavadas nuevamente en agua destilada (Johansen 1940). La epidermis abaxial no fue clareada, ya que quedó transparente después de la disociación química. Se obtuvieron preparaciones semipermanentes con agua glicerinada (1:1), para ser analizadas y fotografiadas en un microscopio Olympus modelo BX 60, con una cámara digital Canon A630.

Para la caracterización anatómica por medio de microscopia electrónica de barrido, los fragmentos de la región media del limbo fueron fijados en solución Karnovsky modificado (Glutaraldeído 2,5\%, formaldehido 2,5\%, buffer cacodilato de sodio $0,05 \mathrm{M}, \mathrm{pH} 7,2, \mathrm{CaCl}_{2} 0,001 \mathrm{M}$ ), $\mathrm{y}$ almacenados en refrigerador por un mes. Las secciones paradérmicas fueron lavadas con un buffer cacodilato y fijadas en tetróxido de osmio $1 \%$ por $2 \mathrm{~h}$, deshidratadas 
en gradiente progresivo de acetona, luego sometidas a un secado a un punto crítico (BAL-TEC, modelo CPD-030, Principality of Liechtenstein), por último montadas en placas de aluminio con doble cinta y metalizadas en evaporador de oro Sputtering (BAL-TEC, modelo SCD-050, Principality of Liechtenstein). Para obtener las secciones transversales, las muestras fueron sumergidas en una solución de glicerol $30 \%$ en agua destilada por $30 \mathrm{~min}$, congeladas en nitrógeno líquido y segmentadas con un bisturí. Las secciones fueron posteriormente fijadas en tetróxido de osmio y preparadas conforme fue descrito anteriormente. Todas las secciones fueron analizadas en microscopio electrónico de barrido (LEO, modelo EVO 40 XVP, Cambrigde-UK).

\section{ANÁLISIS HISTOQUímico}

La caracterización histoquímica de las secciones transversales se realizó mediante el uso de microscopía de luz, los cortes manuales de las secciones de la región media del limbo fueron obtenidos de muestras frescas. La tinción de las secciones se realizó con la finalidad de identificar la presencia y localización de los diferentes compuestos químicos, así: lugol para compuestos con almidón, azul de comassie R250 para proteínas totales, floroglucinol en medio ácido para ligninas, Sudan III para lípidos totales, tetróxido de osmio para lípidos insaturados, ácido sulfúrico para lactonas sesquiterpénicas, dinitrofenilhidrazina para terpenoides con grupo carbonilo, cloruro férrico y dicromato de potasio para compuestos fenólicos generales (ortodihidroxifenoles) y vainillina clorhídrica para taninos (Johansen 1940). Las secciones fueron semipermanentes colocando agua glicerinada (1:1) o en su propio medio, de acuerdo a la especificación del método (Ascensão 2004).

ANÁlisis DE LOS ACEITES ESENCIALES

La muestra utilizada fue de $30 \mathrm{~g}$ de hojas secas sometidas a hidrodestilación en 1 litro de agua destilada en el aparato de Clevenger modificado (Gottlieb \& Magalhães 1960). El hidrolato obtenido fue extraído con diclorometano en una proporción de $1 / 4$ del total, dividido en tres lavados. Como desecante se agregó sulfato de magnesio anhidro durante 24 horas. Después de ese período la solución fue filtrada y mantenida en un frasco de vidrio cubierto con papel aluminio, colocado en el extractor a temperatura ambiente para la evaporación del diclorometano y luego realizada la determinación del porcentaje (\%) de aceite esencial.

Las muestras fueron identificadas en el cromatógrafo de gas acoplado a un espectrómetro de masas CG-EM, Shimadzu QP5050A(Kyoto, Japón), utilizando las siguientes condiciones: columna CBP-5 (Shimadzu) conteniendo sílica (30 mm de largo x 0,25 $\mathrm{mm}$ de diámetro interno x 0,25 $\mu \mathrm{m}$ de espesor, compuesto de fenilmetilpolisiloxano 5\%) y conectada a un detector cuádruplo operado a $70 \mathrm{eV}$, con intervalos de masa entre $40-400 \mu$, a razón de 0,5 scans s $^{-1}$; gas: $\mathrm{He}\left(1 \mathrm{ml} \mathrm{s}^{-1}\right)$; inyector y temperatura de interfase a 220
${ }^{\circ} \mathrm{C}$ y $240{ }^{\circ} \mathrm{C}$, respectivamente, la razón de flujo fue 1:20. El volumen de inyección fue de $0,2 \mu \mathrm{l}\left(20 \%\right.$ en $\left.\mathrm{CH}_{2} \mathrm{Cl}_{2}\right)$ en flujo y temperatura de $60^{\circ} \mathrm{C}$ y $246^{\circ} \mathrm{C}$, con aumento de $3^{\circ} \mathrm{C} \mathrm{min}{ }^{-1}$, $10^{\circ} \mathrm{C} \mathrm{min}^{-1}$ hasta $270^{\circ} \mathrm{C}$, manteniéndose la temperatura final por cinco minutos. La identificación de los constituyentes fue realizada por comparación automática y manuales de los espectros de masas obtenidas en las bibliotecas NIST/EPA/ NIH (1998). La comparación de los espectros de masas e índices de retención (IR) con la literatura de Adams (2001) y la co-inyección con padrones auténticos. Los IR fueron calculados a partir de la co-inyección con una mezcla de hidrocarbonatos y $\mathrm{C}_{8}-\mathrm{C}_{32}$ (Sigma, EUA), además de la aplicación de la ecuación de Van den Dool \& Kratz (1963). Las concentraciones relativas de los compuestos fueron calculadas a partir de las áreas de los picks y expresadas en valores medidos en los tres análisis.

\section{RESULTADOS}

\section{CARACTERIZACIÓN ESTRUCTURAL}

Los haces vasculares de la nervadura central son del tipo colateral abierto, se encontró una reducción de los números de haces vasculares desde la base al ápice de las hojas, presentándose de 1 a 6 a lo largo del limbo (Fig. 1). El aumento del número de haces ocurre exactamente cuando se encuentra una nervadura de segundo orden.

En la región central de la nervadura, el colénquima es angular y se encuentra dispuesto en la superfície abaxial y adaxial de las células subepidérmicas (Fig. 1b-d). A medida que aumenta el número de haces vasculares, el colénquima se restringe a las células subepidérmicas de las regiones ramificadas de la nervadura central (Fig. 1eg). El colénquima encierra un número variado de hileras de células. En la región de transición entre el nervio central y la región media de la hoja, las capas subcelulares son interrumpidas por las células colenquimáticas (Fig. 2). En el mesófilo las células de la nervadura son de menor tamaño, dado que en la nervadura central están rodeadas por una envoltura de células del parénquima, que es simple en las de menor tamaño y doble o el triple pero discontinuas en algunos puntos alrededor de los haces vasculares de la nervadura central.

La sección transversal de la región media de la hoja en P. aduncum (Fig. 2) posee una epidermis adaxial y abaxial de formas variables, con células con una tendencia a ser rectangulares y alargadas en sentido periclinal (Fig. 2a-c). Debajo de ambas epidermis se observó la presencia de una a dos capas de células grandes, desprovistas de cloroplastos (Fig. 2a-c). Esa capa de células es siempre continua y ubicada debajo de la epidermis adaxial; sin embargo, es menor y algunas veces ausente en la parte abaxial (Fig. 2ac). No fue posible la distinción entre hipodermis o epidermis multiseriada, sin embargo, la identificación correcta del 
tejido sólo es posible con un estudio ontogénico de la hoja.

El mesófilo foliar está compuesto de parénquima con clorofila en disposición dorsiventral (Fig. 2b), además de presentar un estrato de parénquima en empalizada, el segundo estrato presenta una transición morfologica entre parénquima en empalizada y esponjoso (Fig. 2b). El parénquima esponjoso está conformado por tres a cuatro capas de células isodiamétricas con disposición aleatoria y con pocos espacios intercelulares del tipo meatos (Fig. 2b).

Se observó la presencia de idioblastos unicelulares de varios tamaños (Fig. 2a-g); a veces mayores a las demás células, que mostraban una distribución variada en la hoja, localizadas sobre una leve depresión al mismo nivel de las células vecinas, principalmente en las capas subcelulares y en el lado abaxial de la epidermis (Fig. 2b), o distribuidos a lo largo del mesófilo (Fig. 2a, 2c, 2f y 2g). Cuando están en el mesófilo los idioblastos tienen forma redonda, cuando están insertos en la epidermis tienen forma ovalada. Los idioblastos están rodeados por células epidérmicas alargadas, dispuestas radialmente en forma de roseta (Fig. 2f y $2 \mathrm{~g}$ ). No se observó la presencia de ningún idioblasto cristalino en la capa subcelular. Algunos idioblastos sobresalen de la epidermis y se pueden ver detalladamente en una vista superior (Fig. 2e).

En la sección paradérmica, las células epidérmicas de ambas superficies foliares tienen forma variada: poligonales, cúbicas y rectangulares, alargadas en el sentido periclinal, con un contorno liso y recubierto por una cutícula delgada (Fig. 3a-f).

Se observó la presencia de estomas sólo en la superficie abaxial del limbo, clasificando como una hoja hipoestomática, con complejos estomáticos tipo tetracíticos (Fig. 3b-c). Como se puede observar en la Figura 3d, los estomas de P. aduncum son sobresalientes.

Se observaron tricomas tectores (Fig. 4a-b) y tricomas glandulares (Figs. 4c-g), distribuidos en ambas superficies del limbo. Los dos tipos de tricomas tectores encontrados fueron: unicelular, corto, de ápice agudo (Fig. 4b) y pluricelular de ápice agudo (Fig. 3a). Los tricomas unicelulares y pluricelulares poseen una base rodeada por células epidérmicas dispuestas en roseta. En el limbo los tricomas unicelulares fueron encontrados en mayor abundancia, mientras que los tricomas pluricelulares estaban restringidos a las nervaduras, y los tricomas capitados solamente a la nervura central, siendo aún más raros.

Los tricomas glandulares son de tres tipos morfológicos: a) con pedúnculo nítido y parte secretora unicelular y de forma globular (Fig. 4d-e); b) con pedúnculo más corto e insertado entre las células epidérmicas y la parte secretora ovoide, cubierto con una cutícula curvada sobre la epidermis (Fig. 4f y 4g) y c) con base similar al tricoma pluricelular, y con una parte secretora ovoide en las extremidades del ápice (Fig. 4c). El más común fue el tricoma glandular ovoide, que se encontró distribuido en ambas superficies del limbo. Tanto los tricomas glandulares globulares como pluricelulares capitados son raros y localizados sólo en la epidermis abaxial. El tricoma glandular globular, por un proceso de abscisión, presenta una cicatriz, como se puede ver en la Figura 4e (flecha).

\section{AnÁLISIS HISTOQUímico}

Se verificó la presencia de almidón (Fig. 5a-c) en todo el tejido en empalizada y esponjoso de mesófilo foliar (Fig. 5a) y en menor cantidad en el parénquima fundamental de la nervadura central, especialmente cerca de los haces vasculares (Fig. 5b). El almidón se encontró almacenado en grandes gránulos que ocupan casi todo el cloroplasto, distribuidos a lo largo de las células del tejido en empalizada y esponjoso. La presencia fue confirmada en las células guarda de los estomas (Fig. 5a, flecha).

Proteínas totales fueron encontradas en todo el limbo, excepto en los parénquimas en empalizada y esponjoso (Fig. 5d-h, 5j). Las proteínas fueron encontradas en la porción basal de los tricomas tectores (Fig. 5f) y en la porción secretora de los tricomas globulares (Fig. $5 \mathrm{~g}$ y $5 \mathrm{~h}$ ), no fueron detectadas en la glándula perlada (Fig. 5i) ni en los idioblastos oleíferos (Fig. 5j).

Únicamente en el parénquima empalizada y esponjoso se demostró la presencia de lípidos insaturados (Fig. 5kp), mientras que la presencia de lípidos totales se observó en todo el parénquima del limbo (Fig. 5q-t), en la porción secretora de los tricomas globulares (Fig. 5s) y en los idioblastos oleíferos (Fig. 5t).

La presencia de lignina se limitó a las fibras sobre el floema y en las paredes del xilema (Fig. 6a-b), los taninos estuvieron ausentes (Fig. 6c). En los idioblastos oleíferos, se detectó la presencia de ortodihidroxifenoles (Fig. 6d-h), lactonas sesquiterpénicas (Fig. 6i) y terpenoides con grupo carbonilo (Fig. 6j). Distribuidos al azar en el parénquima fundamental, también se encontraron ortodihidroxifenoles (Fig. 6g) y terpenoides con grupo carbonilo (Fig. 6k). En los tricomas saculares sólo se encontraron ortodihidroxifenoles (Fig. 6h).

El resumen de la histolocalización se presenta en la Tabla I. La histolocalización de los compuestos del metabolismo secundario puede ser observada en la Tabla II. 


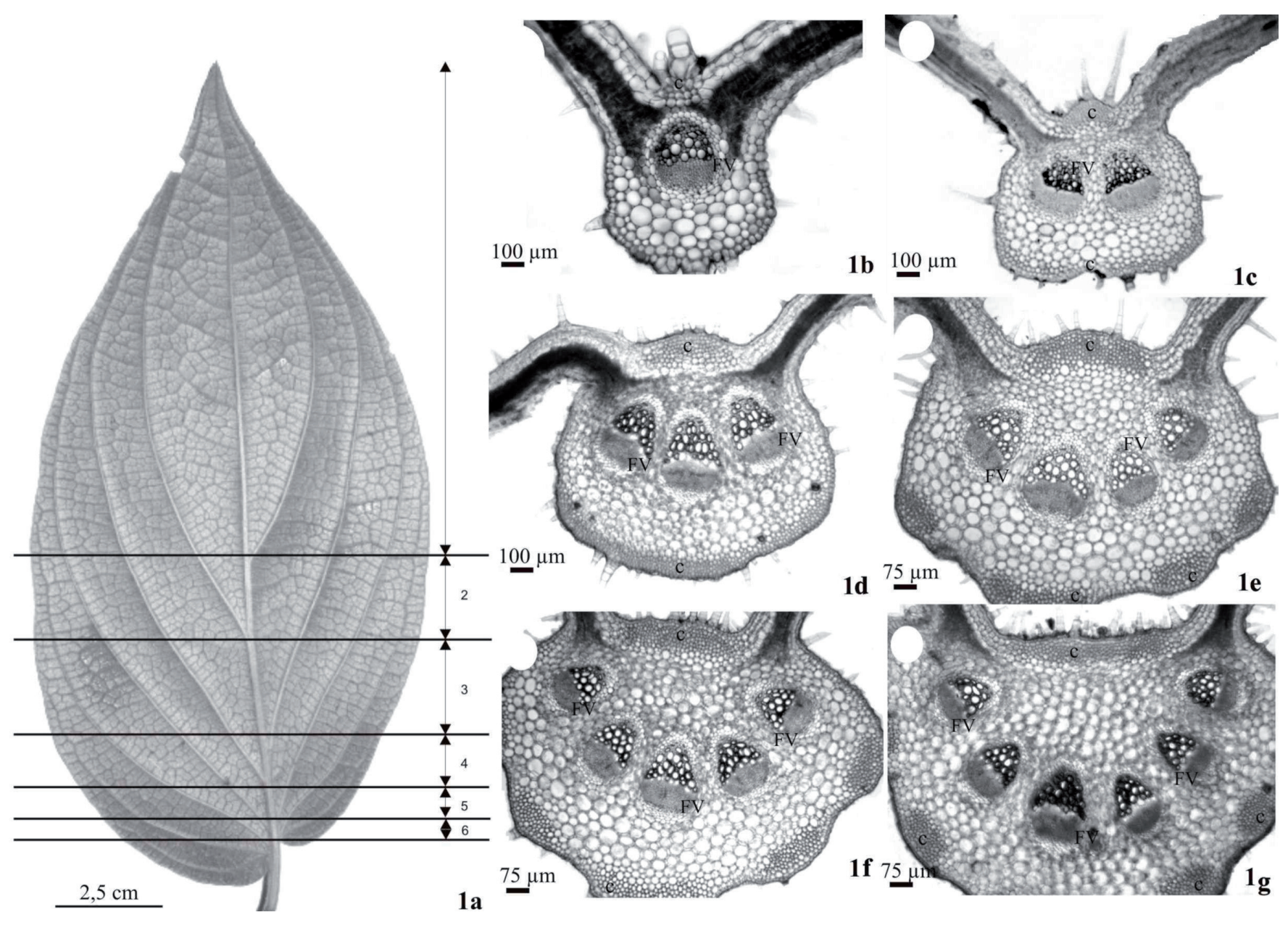

FigURA 1. (a) Fotografía de una hoja indicando las regiones con un aumento progresivo del número de haces vasculares, desde el ápice hacia la base de Piper aduncum, (b-g) Fotomicrografias de la nervadura central mostrando el aumento en el número de haces vasculares en cada intervalo, entre el encuentro con la nervadura principal y las de segundo orden. C: Colénquima, FV: Paquete vascular.

FiguRE 1. (a) Photograph of a sheet indicating the regions with progressively increasing number of vascular bundle, the meaning is the apex to the base of Piper aduncum, (b-g) photomicrograph of midrib showing the increase in the number of bundle in each vascular interval between the encounter with the main ribs and the second order. C: Collenchyma, FV: Vascular bundle. 

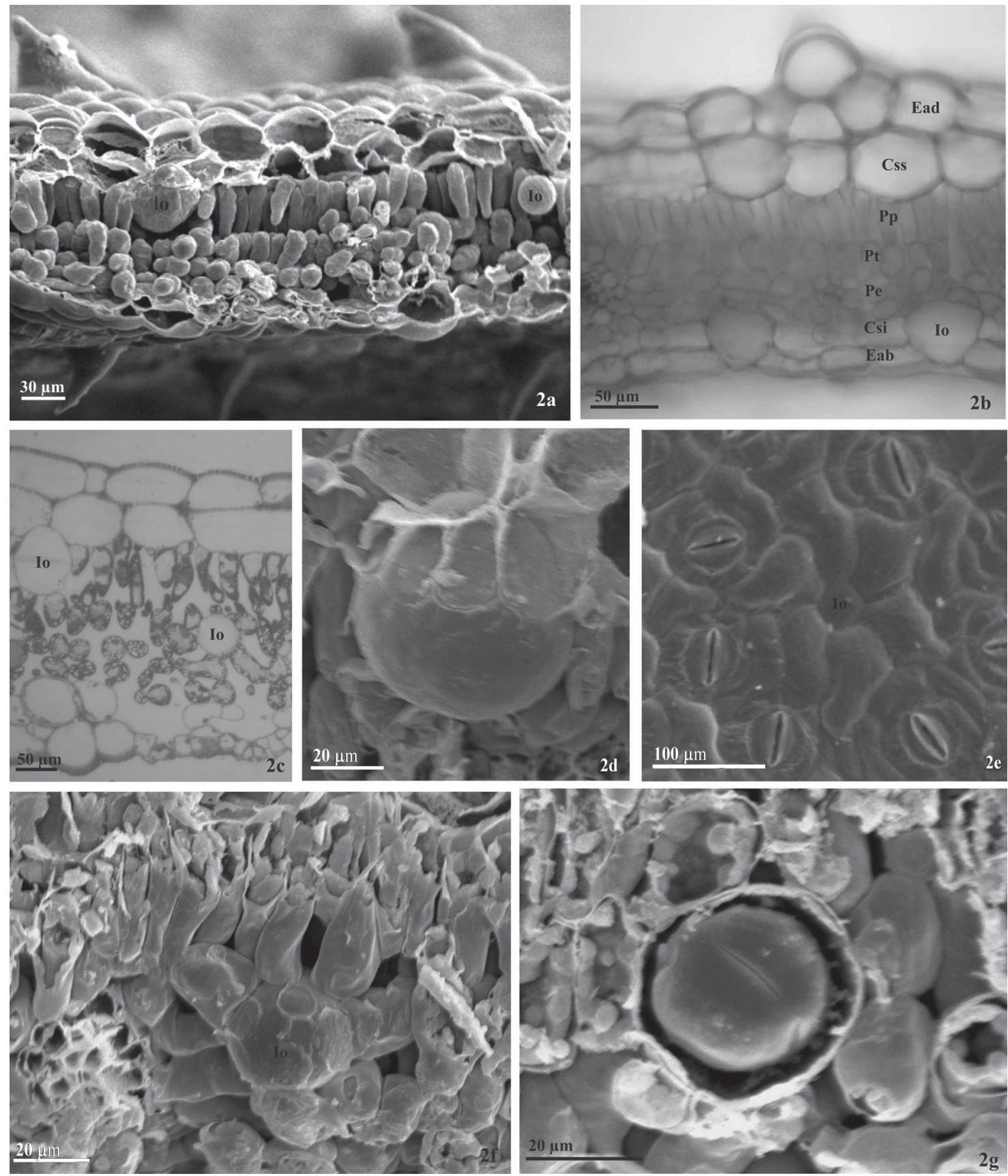

Figura 2. Detalle de la sección transversal (Figuras a-e, g) y de la paradérmica (f) del limbo de Piper aduncum. (a) Microscopía electrónica de barrido, (b-c) Fotomicrografía, (d) Microscopía electrónica de barrido evidenciando la presencia de idioblasto oleífero, (e) Microscopía electrónica de barrido evidenciando la parte superior del idioblasto oleífero, (f) Microscopía electrónica de barrido mostrando el idioblasto oleífero insertado en el mesófilo, (g) Microscopía electrónica de barrido evidenciando el idioblasto oleífero del mesófilo, exponiendo el contenido interno y numero de granos de almidón en los parénquimas. Csi: Capa subcelular inferior, Css: Capa subcelular superior, Eab: Epidermis abaxial, Ead: Epidermis adaxial, Io: Idioblasto oleífero, Pe: Parénquima esponjoso, Pp: Parénquima en empalizado, Pt: Parénquima de transición.

Figure 2. Detail of the transverse section (Figures a-e, g) and paradermic (f) of the lamina of Piper aduncum. (a) Scanning electron microscopy, (b-c) micrograph, (d) Scanning electron microscopy showing the presence of oil idioblasts, (e) Scanning electron microscopy showing the top of oil idioblasts, (f) Scanning electron microscopy showing the inserted oil idioblasts in the mesophyll, (g) Scanning electron microscopy showing the mesophyll oil idioblasts, exposing the internal contents and numerous grains of starch in the parenchyma. Csi: Subcellular lower layer, Css: Subcellular upper layer higher, Eab: abaxial epidermis, Ead: adaxial epidermis, Io: Oil idioblasts, Pe: spongy parenchyma, Pp: palisade parenchyma, Pt: transitional parenchyma. 

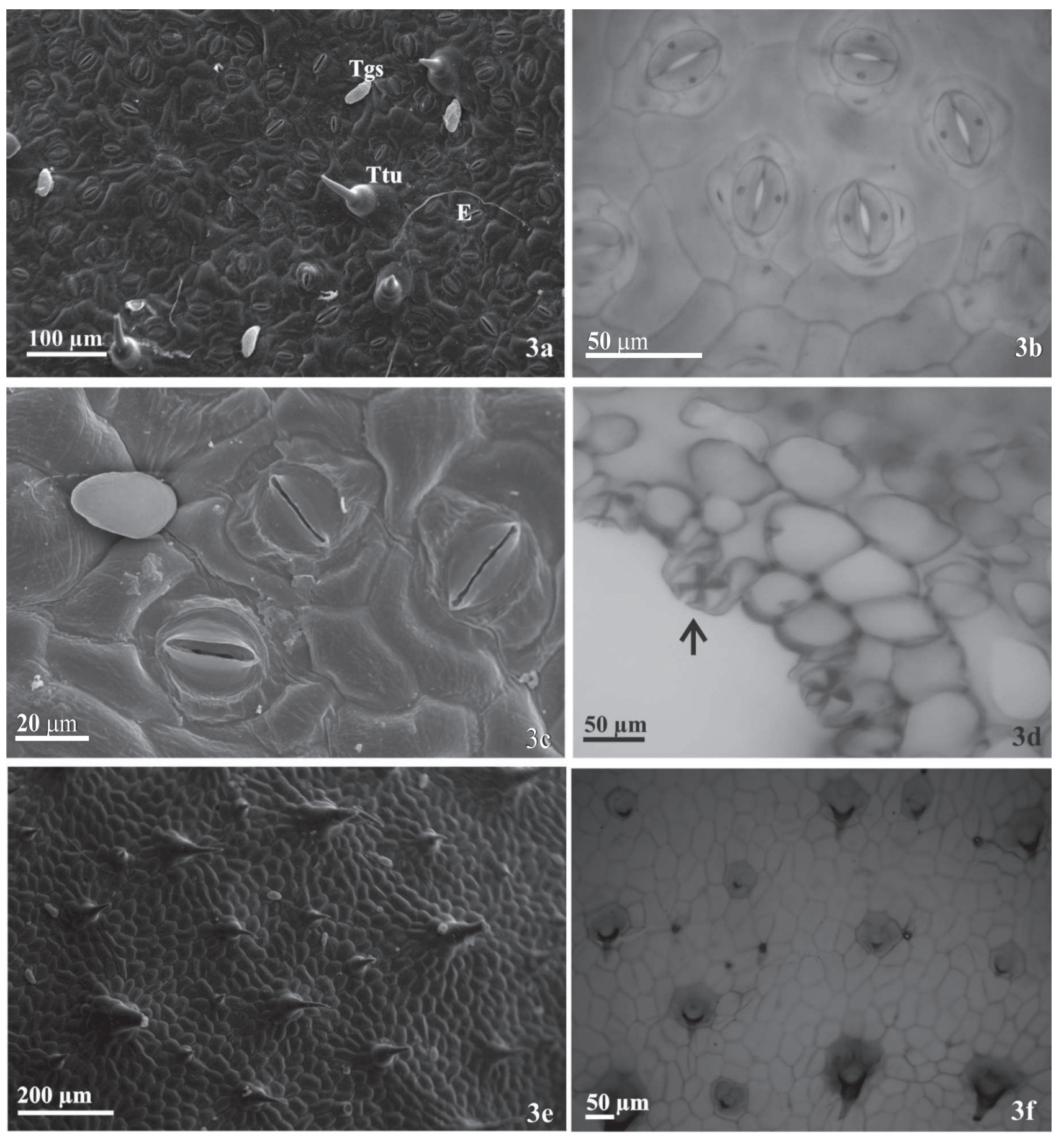

Figura 3. Sección paradérmica (3a-c y 3e-f) y transversal (3d) del limbo Piper aduncum. (a) Microscopía electrónica de barrido de la superficie abaxial, (b) Fotomicrografía con evidencia de estomas tetracíticos, (c) Microscopía de barrido con evidencia de estomas tetracíticos, (d) Fotomicrografía con evidencia de los estomas salientes (flecha), (e) Microscopía de barrido de la superficie adaxial, (f) Fotomicrografía de la superficie adaxial. E: Estomas, Tgs: Tricoma glandula sacular, Ttu: Tricoma tector unicelular.

Figure 3. Paradermic section (3a-c and 3e-f) and transverse (3d) of Piper aduncum limbo. (a) Scanning electron microscopy of abaxial surface, (b) Photomicrograph with evidence of stomata tetracytic, (c) scanning microscopy evidence tetracytic stomata, (d) Photomicrograph with evidence of stomata projections (arrow), (e) Scanning electron microscopy of adaxial surface, (f) Photomicrograph of the adaxial surface. E: Stomata, Tgs: Sac-like trichomes, Ttu: Unicellular tector trichomes. 

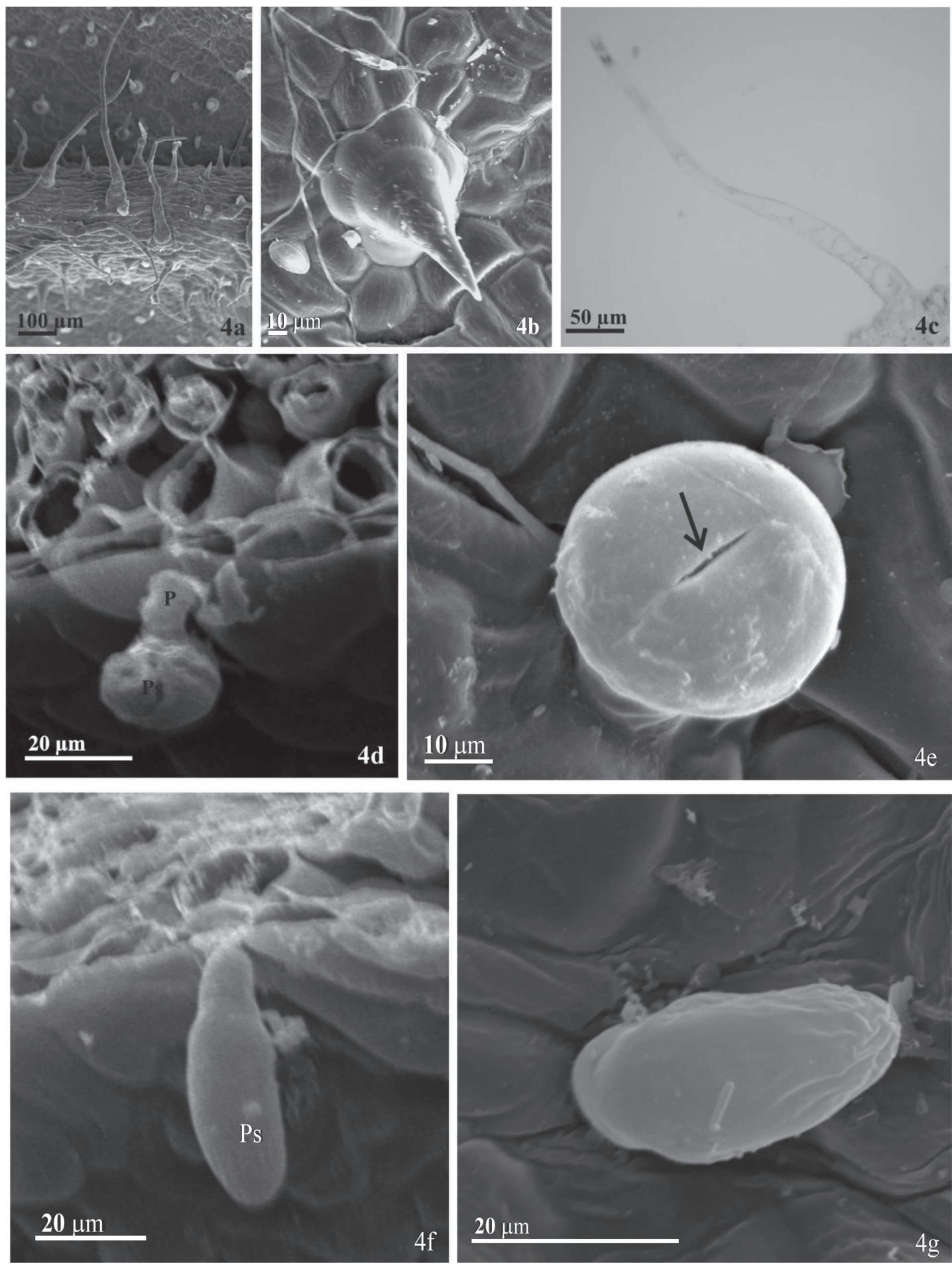

FIGURA 4. Microscopía electrónica de barrido (4a-b, y 4d-g) de la sección paradérmica y transversal de la superfície abaxial y fotomicrografia (4c) de la sección transversal del limbo de Piper aduncum. (a) Evidencia de la nervadura media recubierta por tricomas tectores, (b) Tricoma tector unicelular, (c) Tricoma tector capitado, (d-e) Tricoma glandular globular, (f-g) Tricoma glandular fusiforme. P: Pedúnculo, Ps: Parte secretora unicelulares.

FIGURE 4. Scanning electron microscopy (4a-b, and 4d-g) paradermic and transverse section of the abaxial surface and photomicrograph (4c) of the transverse section from the limbo of Piper aduncum. (a) Evidence of the midrib covered with tector trichomes, (b) Unicellular tector trichome, (c) Capitate tector trichomes, (d-e) Globular glandular trichome (f-g) Fusiform glandular trichome. P: Shank, Ps: Unicellular secretory part. 

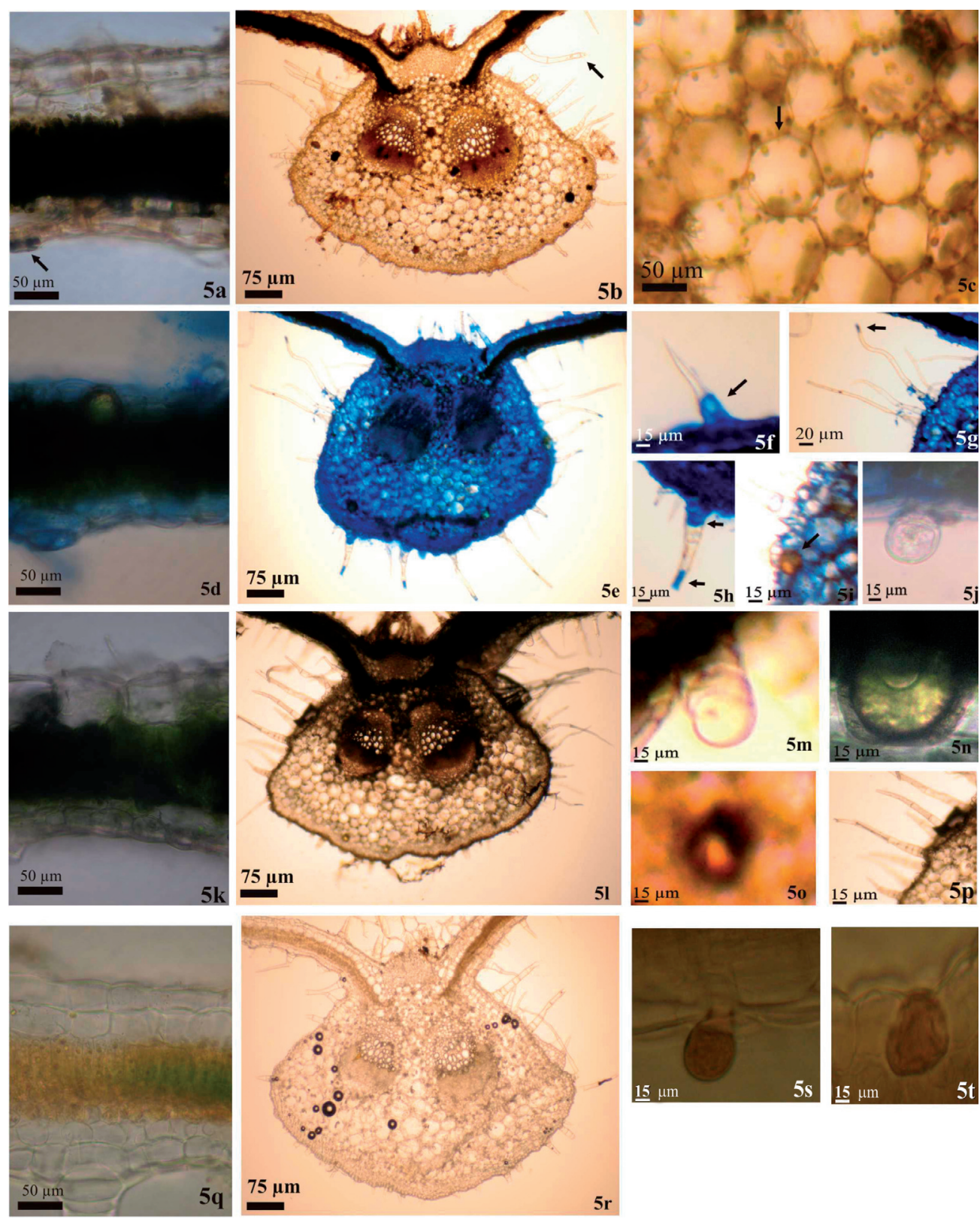

FiguRa 5. Fotomicrografia de las secciones transversales del limbo de Piper aduncum, teñidas con lugol (5a-c), azul de comassie (5d-j), tetroxido de osmio (5k-p) y Sudan (5q-t). (a) Mesófilo y célula oclusiva (flecha) intensamente teñidos de rojo, (b) Nervadura central con tricoma glandular sacular (flecha) y tricomas tectores sin teñir, (c) Parénquima fundamental con acúmulo de almidón (flecha), (d) Mesófilo no teñido de azul, (e) Nervadura central con parénquima fundamental intensamente teñido, (f) Tricoma tector evidenciando base teñida (flecha), (g) Tricoma glandular sacular evidenciando porción secretora teñida (flecha), (h) Tricoma glandular sacular evidenciando porción secretora y base teñida (flecha), (i) Tricoma glandular globular no teñido, (j) Célula oleosa no teñida (flecha), (k) Mesófilo teñido de negro, (l) Nervadura central, (m) Tricoma glandular globular no teñido, (n-o) Célula oleosa no teñida, (p) Tricomas no teñidos, (q) Mesófilo teñido de castaño, (r) Nervadura central, (s) Tricoma glandular sacular con porción secretora teñida, (t) Célula oleosa teñida.

Figure 5. Photomicrograph of transverse sections of the limbo of Piper aduncum, stained with iodine (5a-c), blue comassie (5d-j), osmium tetroxide (5k-p) and Sudan (5q-t). (a) Mesophyll and guard cells (arrow) stained intensely red, (b) Midrib with evidence sac-like glandular trichomes (arrow) and unstained tector trichomes, (c) Fundamental parenchyma starch accumulation (arrow), (d) No bluestained mesophyll, (e) Midrib fundamental parenchyma intensely stained, (f) Showing trichome base detector stained (arrow), (g) Sac-like showing glandular trichome secretory portion stained (arrow), (h) Glandular trichome showing sac-like secretory portion and base stained (arrow), (i) Unstained globular glandular trichomes, (j) Unstained cell oil (arrow), (k) Mesophyll dyed black, (l) Midrib, (m) Glandular trichome globular no dyeing, (no) Unstained cell oil, (p) Trichomes not stained, (q) Mesophyll stained brown, (r) Midrib, (s) Sac-like glandular trichome secretory proportion stained, (t) Stained cell oil. 

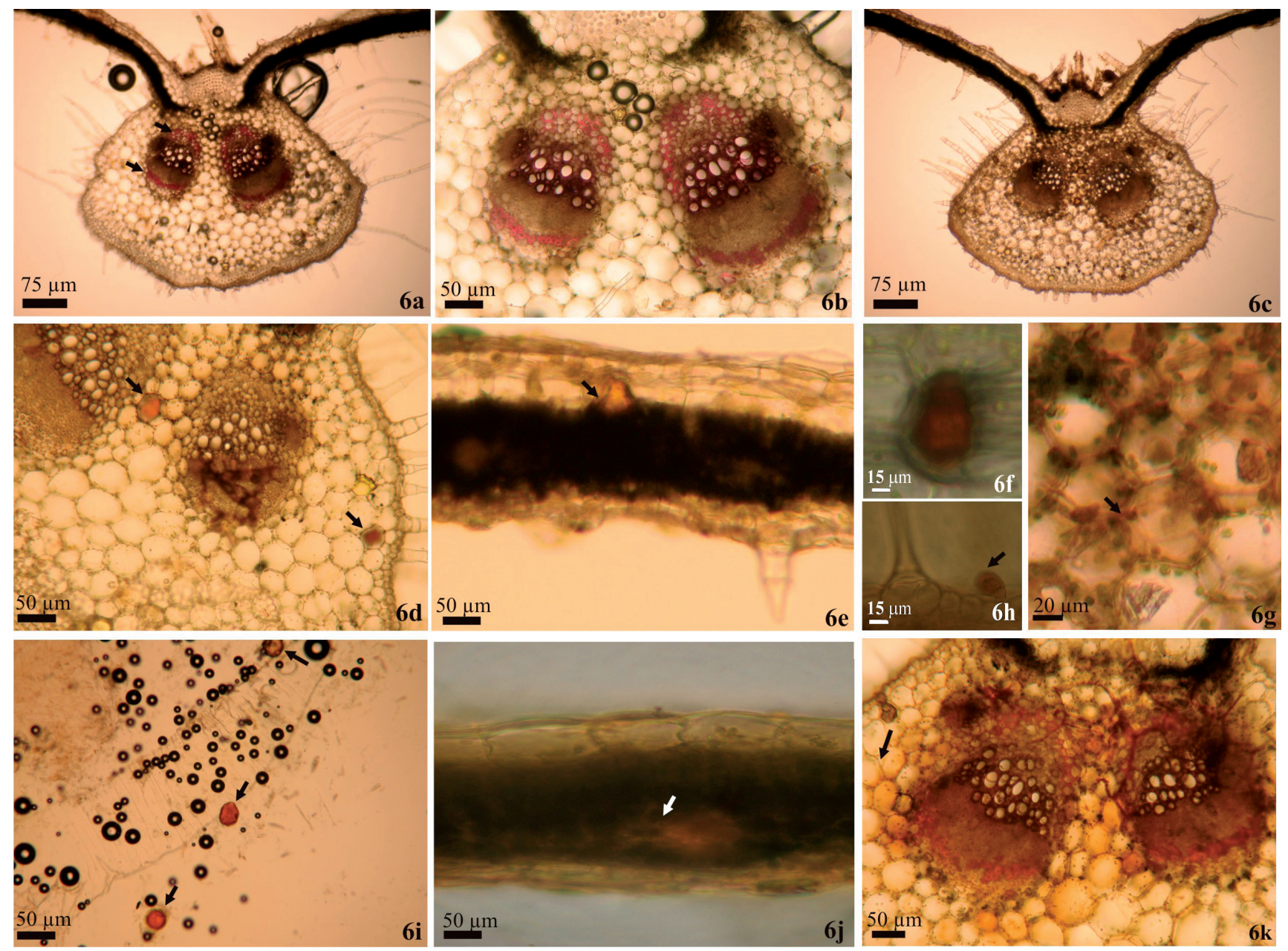

Figura 6. Fotomicrografía de las secciones transversales del limbo de Piper aduncum, teñidas con floroglucinol en medio ácido (6a-b), vainillina clorhídrica (6c), cloruro férrico o dicromato de potasio (6d-h), ácido sulfúrico (6i) y dinitrofenilhidrazina (6j-k). (a) Nervadura central con evidencia de lignina asociada sólo a los haces vasculares (flecha), (b) Detalle de los haces vasculares conteniendo lignina, (c) Reacción negativa para tanino, (d) Nervadura central con evidencia de idioblasto oleífero conteniendo ortodihidroxifenoles (flecha), (e) Mesófilo con idioblasto oleífero teñido (flecha), (f) Detalle del idioblasto oleífero teñido, (g) Compuestos fenólicos en el parénquima fundamental (flecha), (h) Tricoma sacular con la porción secretora teñida (flecha), (i) Idioblasto oleífero teñido (flecha), (j) Idioblasto oleífero teñido (flecha), (k) Terpenoides en el parénquima fundamental (flecha).

Figure 6. Photomicrograph of transverse sections of the lamina of Piper aduncum, stained with phloroglucinol in acid (6a-b), vanillin hydrochloride (6c), ferric chloride or potassium dichromate (6d-h), sulfuric acid (6i) and dinitrophenylhydrazine (6j -k). (a) Midrib with evidence of associated lignin only to the vascular bundles (mushroom), (b) Detail of vascular bundles containing lignin, (c) Negative reaction for tannin, (d) Midrib with evidence of idioblasts containing oily orthodihydroxyphenols (arrow), (e) Mesophyll idioblasts oil with stained (arrow), (f) Detail of oil idioblasts stained, (g) Phenolic compounds in fundamental parenchyma (arrow), (h) Sac-like trichome stained with the secretory portion (arrow), (i) Oil idioblasts stained (arrow), (j) Oil idioblasts stained (arrow), (k) Terpenoids in the fundamental parenchyma (arrow). 
Caracterización del limbo de Piper aduncum: Dousseau, S. ET AL.

TABLA I. Histolocalización de almidón, proteínas y lípidos en hojas de Piper aduncum, mediante ensayos histoquímicos.

TABLE I. Histolocalization starch, proteins and lipids in leaves of Piper aduncum through histochemical tests.

\begin{tabular}{lcccc}
\hline Tejido/estructura andtómica & Almidón & Proteínas totales & Lípidos insaturados & Lípidos totales \\
\hline Epidermis & - & + & - & - \\
Capa subcelular & - & + & - & - \\
Parénquima en empalizada & + & - & + & + \\
Parénquima esponjoso & + & - & - & + \\
Idioblastos oleíferos & - & - & - & + \\
Parénquima fundamental & + & + & - & - \\
Célula de guarda & + & $*$ & - & + \\
Tricoma tector & - & + & $*$ & $*$ \\
Tricoma globular & - & + & \\
Glándula perlada & - & &
\end{tabular}

El contenido de aceite esencial de las hojas de P. aduncum fue $0,63 \%$ predominando compuestos terpenoides (Tabla III). Los monoterpenos componen el 53\% del aceite esencial y son representados por el linalol (mayor compuesto). Los sesquiterpenos conforman el 55\% del contenido del aceite esencial y son representados por diversos compuestos, especialmente el óxido de cariofileno, epóxido II de humuleno, (E) Nerolidol y a-Copaeno. También estaban presentes pequeñas cantidades de alil benzeno safrol y de metil cetona 2- Undecanona.

TABLA II. Histolocalización de compuestos fenólicos y terpénicos en hojas de Piper aduncum, por medio de ensayos histoquímicos.

TABLE II. Histolocalization of phenolic compounds and terpenes in leaves of Piper aduncum through histochemical tests.

\begin{tabular}{|c|c|c|c|c|c|}
\hline \multirow{2}{*}{ TEJIDO/ESTRUCTURA ANATÓMICA } & \multicolumn{3}{|c|}{ COMPUESTOS FENÓLICOS } & \multicolumn{2}{|c|}{ COMPUESTOS TERPÉNICOS } \\
\hline & LignINA & TANINOS & $\begin{array}{l}\text { ORTODIHI- } \\
\text { DROXIFENOLES }\end{array}$ & $\begin{array}{l}\text { LACTONAS } \\
\text { SESQUITERPENAS }\end{array}$ & $\begin{array}{l}\text { TERPÉNICOS CON } \\
\text { GRUPO CARBONILO }\end{array}$ \\
\hline Epidermis & - & - & - & - & - \\
\hline Capa subcelular & - & - & - & - & - \\
\hline Parénquima en empalizada & - & - & - & - & - \\
\hline Parénquima esponjoso & - & - & - & - & - \\
\hline Idioblastos oleíferos & - & - & + & + & + \\
\hline Parénquima fundamental & - & - & + & - & + \\
\hline Célula de guarda & - & - & - & - & - \\
\hline Tricoma tector & - & - & - & - & - \\
\hline Tricoma globular & - & - & + & - & - \\
\hline Glándula perlada & - & - & $*$ & $*$ & $*$ \\
\hline
\end{tabular}


TABLA III. Composición química (\%) del aceite esencial extraído de las hojas de Piper aduncum.

TABLE III. Chemical composition (\%) of essential oil extracted from the leaves of Piper aduncum.

\begin{tabular}{|c|c|c|c|c|}
\hline $\mathrm{TR}$ (min) & Compuesto & $(\%)$ & IRR exp.* & IRR lit.** \\
\hline 11,475 & cis-Óxido de Linalol & 2,97 & 1070 & 1072 \\
\hline 12,067 & Trans-Óxido de Linalol & 1,8 & 1086 & 1086 \\
\hline 12,558 & Linalol & 48,02 & 1099 & 1096 \\
\hline 19,467 & Safrol & 0,67 & 1288 & 1287 \\
\hline 19,617 & 2-Undecanona & 0,8 & 1292 & 1294 \\
\hline 21,475 & a-Cubebeno & 0,44 & 1346 & 1348 \\
\hline 21,775 & No identificado & 0,44 & 1354 & - \\
\hline 22,467 & a-Copaeno & 3,52 & 1374 & 1376 \\
\hline 25,133 & a-Humuleno & 0,68 & 1454 & 1454 \\
\hline 25,275 & Allo-Aromadendreno & 0,54 & 1458 & 1460 \\
\hline 25,767 & g-Muuroleno & 0,39 & 1473 & 1479 \\
\hline 26,233 & b-Selineno & 0,68 & 1487 & 1490 \\
\hline 26,450 & No identificado & 2,27 & 1494 & - \\
\hline 26,542 & a-Muuroleno & 0,49 & 1497 & 1500 \\
\hline 27,083 & g-adineno & 1,21 & 1514 & 1513 \\
\hline 28,517 & (E) Nerolidol & 4,63 & 1560 & 1563 \\
\hline 29,000 & Espatulenol & 0,84 & 1576 & 1578 \\
\hline 29,167 & Oxido de Cariofileno & 15,88 & 1581 & 1583 \\
\hline 30,025 & Epóxido II de Humuleno & 12,85 & 1609 & 1608 \\
\hline 31,825 & No identificado & 0,85 & 1670 & - \\
\hline
\end{tabular}

* El resultado obtenido en el experimento / The result obtained in the experiment.

** Resultados descritos en la literatura / Results described in the literature.

\section{DISCUSIÓN}

Vianna \& Akisue (1997) realizaron estudios con individuos de Piper aduncum del Estado de São Paulo, Brasil, observando un aumento en el número de haces vasculares de la nervadura central del ápice a la base foliar, confirmando lo reportado en $P$. diospyrifolium (Souza et al. 2004), $P$. crassinervium (Albiero et al. 2005a), P. gaudichaudianum (Albiero et al. 2005b) y P. hispidum (Albiero et al. 2006). Sin embargo, en cuanto a los haces vasculares primarios y secundarios no hubo relación.

Vianna \& Akisue (1997) relatan que en $P$. aduncum el colénquima es angular, siempre continuo, formado por ocho a nueve hileras de células en la superfície abaxial y de cuatro a cinco hileras de células en la superficie adaxial, independientemente de la región del limbo.

La presencia de colénquima angular en la región subepidérmica de la nervadura central es bastante común en las especies del género Piper, siendo la mayoría de las veces continuo (Albiero et al. 2005a, Albiero et al. 2005b), mientras que en $P$. hispidum (Albiero et al. 2006) existe una banda muy reducida de colénquima en la superfície adaxial del ápice de la hoja.

La existencia de una capa subcelular es común y bastante discutida entre las Piperaceae. Vianna \& Akisue (1997) observaron la presencia de una capa subcelular en la epidermis adaxial y la denominaron hipodermis sin contenido, mediante estudios ontogénicos en hoja. Souza et al. (2004), en estudios ontogénicos de las hojas de $P$. diospyrifolium, verificaron la existencia de divisiones periclinales en la protodermis, formando una epidermis adaxial multiseriada.

En P. crassinervium, Albiero et al. (2005a) verificaron la presencia de una capa subepidérmica en ambas epidermis $\mathrm{y}$ en el estudio ontogénico observaron raras divisiones periclinales en las células protodérmicas; sin embargo, no concluyeron si es hipodermis o epidermis múltiple. Albiero et al. (2005b) también verificaron la presencia de una o dos capas subepidérmicas, en ambas superficies foliares de $P$. gaudichaudianum, sin concluir la naturaleza de las capas con estudio ontogénico. En P. hispidum, Albiero et al. (2006) encontraron que la capa subcelular en ambas 
superficies fue descontinua en la cara adaxial (con una a tres capas) y débilmente continua en la cara abaxial (con dos a tres capas). Esa estructura fue denominada hipodermis, aunque no se hizo un estudio ontogénico de la hoja.

No se observó la presencia de idioblasto cristalino en la capa subcelular, a diferencia de Vianna \& Akisue (1997), que encontraron cristales de oxalatos de calcio aciculares y cristales prismáticos en $P$. aduncum.

El mesófilo dorsiventral y el parénquima en empalizada uniestratificado son características comunes en Piperaceae; por esto el número de las capas del tejido esponjoso es muy variable, como se menciona más adelante. Vianna \& Akisue (1997) observaron en P. aduncum de cuatro a cinco estratos de células en el parénquima esponjoso y en los espacios intercelulares del tipo meatos. Souza et al. (2004), en $P$. diospyrifolium y Albiero et al. (2005a) en P. crassinervium, verificaron la presencia de tres a cuatro capas de células; Albiero et al. (2005b) encontraron dos a tres estratos de parénquima esponjoso en $P$. gaudichaudianum; y Albiero et al. (2006) observaron de dos a cuatro estratos en $P$. hispidum. De manera similar a lo planteado por Marinho (2008), en Pothomorphe umbellata, la anatomía foliar de Piper aduncum está directamente relacionada con el ambiente. Posee células con cutícula delgada, estomas salientes y escasa lignificación, probablemente relacionada con el ambiente húmedo característico de esta especie.

De acuerdo con Fahn (1990) y Esau (1985), el parénquima esponjoso muestra una organización más variada que el parénquima en empalizado, este último es pluriestratificado, la capa más interna presenta forma y disposición semejantes con el parénquima esponjoso, como fue observado en P. aduncum.

Algunos idioblastos sobresalen de la epidermis y se pueden ver detallados en la vista superior (Fig. 2e), tal resultado fue observado por Marinho (2008) en Pothomorphe umbellata (L.) Miq. (Piperaceae). La presencia de idioblastos oleíferos es muy común entre las especies del genero Piper, sin embargo, la ubicación es variable. En el trabajo de Vianna \& Akisue (1997), con P. aduncum, denominaron esos idioblastos como células oleosas y sólo relataron la frecuencia de insertos en el mesófilo, como lo observado en P. crassinervium (Albiero et al. 2005a) y P. hispidum (Albiero et al. 2006). De acuerdo con Nascimento \& Vilhena-Potiguara (1999) y Albiero et al. (2005b), en Piper hispidinervium y Piper gaudichaudianum respectivamente, esas estructuras fueron encontradas en el mesófilo y las capas subcelulares, en cuanto a Piper regnellii (Miq.) C. DC. var. pallescens (C.DC.) Yunck. (Pessini et al. 2003), fue verificada solamente en la capa subcelular.

En la sección paradérmica, las células epidérmicas de ambas superficies foliares tienen forma variada (poligonales, cúbicas y rectangulares, alargadas en el sentido periclinal, con contorno liso y cubierto por una cutícula delgada (Fig. 3a-c, 3e y $3 \mathrm{f}$ ), comprobando lo descrito por Albiero et al. (2005a) para P. crassinervium. Vianna \& Akisue (1997) describen que las células de la epidermis abaxial de $P$. aduncum poseen un contorno sinuoso, mientras que la adaxial un contorno liso, semejante al descrito por Albiero et al. (2005b), para P. gaudichaudianum.

La baja intensidad luminosa del ambiente de desarrollo de algunas plantas pueden llevar al aumento de la sinuosidad de las paredes anticlinales de las células epidérmicas, favoreciendo su desarrollo en ambientes sombríos, una vez aumentada la superficie específica de absorción de la luz (Castro \& Pereira 2007). Ese factor pudo contribuir en las diferencias encontradas por Vianna \& Akisue (1997).

Vianna \& Akisue (1997) encontraron estomas anomocíticos además de los tetracíticos. Las hojas hipoestomáticas y los estomas tetracíticos han sido encontrados en diversas especies del género Piper, como $P$. diospyrifolium (Souza et al. 2004), P. crassinervium (Albiero et al. 2005a), P. gaudichaudianum (Albiero et al. 2005b) y P. hispidum (Albiero et al, 2006). En estas especies fueron observados otros tipos de estomas, como ciclocíticos para P. crassinervium (Albiero et al. 2005a) y raros anisocíticos para P. hispidum (Albiero et al. 2006).

Como se puede observar en la Figura 3d, los estomas de $P$. aduncum son sobresalientes, hecho no descrito en otras especie del género Piper. Según Castro \& Pereira (2007), la posición de los estomas posee una función ecológica, cuando están ubicados arriba de las demás células epidérmicas se asocian a un suministro hídrico grande (hidrófitas), mientras que los estomas ubicados en las depresiones a baja disponibilidad hídrica (xerófitas). Lo anterior coincide con lo encontrado en esta especie, que según Lorenzi \& Matos (2002) es umbrófila, encontrada en varias formas boscosas, preferencialmente en suelos con un elevado contenido de materia orgánica y humedad, similar a la ubicación donde se colectó el material de estudio.

El tricoma glandular globular se asemeja a las glándulas peroladas encontradas por Silva \& Machado (1999) durante la realización de estudios ontogénicos de $P$. regnellii var. regnellii, afirmando que esta situación es común en las primeras etapas de desarrollo y rara en la maduración de la hoja. Ese tipo de tricoma fue descrito para $P$. regnellii var. pallescens (Pessini et al. 2003), y encontrado con mayor frecuencia en las hojas jóvenes.

El tricoma glandular ovoide fue similar al descrito por Silva \& Machado (1999), como tricoma sacular. En este trabajo los autores muestran que la base de ese tipo de tricomas se desarrolla y posteriormente se convierten en tricomas glandulares capitados. La presencia de tricoma glandular ovoide es bastante común dentro de las Piperaceae (Vianna \& Akisue 1997, Nascimento \& Vilhena-Potiguara 1999, Pessini et al. 2003, Albiero et al. 2005a, Albiero et al. 2005b, Albiero et al. 2006).

Corroborando los resultados de este estudio, Pessini et al. (2003) reportaron la presencia de almidón, así como lípidos 
totales, lactonas sesquiterpénicas y ligninas, en el limbo de $P$ regnellii var. pallescens; sin especificar la localización de los compuestos.

El contenido del aceite esencial de las hojas de $P$. aduncum, encontradas en este estudio fue de 0,63\%, los compuestos predominantes y presentes en mayor proporción fueron terpenoides y el monoterpeno linalol, coincidiendo con la literatura consultada. Sin embargo, en algunos estudios ha sido predominante la presencia fenilpropanoide dilapiol, con un rendimiento de aceite variable, como se observó en la región occidental de Cuba, con $0,96 \%$ de rendimiento y $82,2 \%$ de dilapiol (Pino et al. 2004), en el Estado de Acre, donde se reporta cerca de 2\% de rendimiento y 73,97\% de dilapiol (Fazolin et al. 2005, Estrela et al. 2006; Fazolin et al. 2007), y en el Estado de Pará, con el $2,5 \%$ de rendimiento y el $88,9 \%$ de dilapiol (Sousa et al. 2008). También hay plantas con niveles más bajos de dilapiol, como en Papua Nueva Guinea, con 0,35\% de rendimiento y el 43,3\% de dilapiol al (Rali et al. 2007) y en Macas, Ecuador, con el 0,8\% rendimiento y 45,92\% de dilapiol (Guerrini et al. 2009).

Por otra parte, otros trabajos sobre aceites en plantas mencionan la presencia de una mezcla de monoterpenos y sesquiterpenos, pero una carencia de dilapiol como se encuentra en las plantas del Estado de Minas Gerais, donde su rendimiento fue de $0,7 \%$ de aceite esencial (Mesquita et al. 2005), y en el Estado de Sao Paulo, con un rendimiento del 2\% (Navickiene et al. 2006). En el estado de Pernambuco, también se encontraron plantas de rendimiento entre 1,2 a $2,5 \%$ y con una predominante presencia de sesquiterpeno E - nerolidol, con un nivel cerca de un $80 \%$ (Oliveira et al., 2006).

Las descripciones de la especie $P$. aduncum que crecen en diferentes países también indican dilapiol como componente principal, con un porcentaje de 64,5\% en Malasia (Jantan et al. 1994), 90,0\% en Panamá (Gupta et al. 1983), y 58,0\% en Fiji (Smith \& Kassim 1979). Para las muestras recolectadas en dos lugares diferentes en Costa Rica (Turrialba y San José), los principales componentes eran dilapiol $(37,1 \%$, $61,8 \%)$, piperitona $(11,1 \%, 2,2 \%), 1,8$ - cineol $(0,1 \%$, $5,8 \%)$ y 4 -terpineol $(4,4 \%, 1,6 \%)$, respectivamente (Ciccio \& Ballestero 1997). Mesquita et al. (2005) estudiaron el aceite volátil de $P$. aduncum en poblaciones recolectadas en el Parque Estatal Rio Doce (Atlántico), no se encontró este compuesto como la mayoría, pero si el (E) nerolidol con un 14,2\%. Por otro lado, Maia et al. (1998) en análisis de la misma especie con el material vegetal recolectado en la región del Amazonas, no encontraron el compuesto E-nerolidol en el análisis de los aceites esenciales de hojas y frutos, pero encontraron la presencia del compuesto principal como dilapiol, en un rango de 33 a $62 \%$. Gaia et al. (2004) estudiaron 18 accesiones de P. aduncum recolectadas en cuatro ciudades de la Amazonia brasileña, destacadas por una diversidad real entre las 27 poblaciones analizadas.
Las diferencias ambientales en los lugares donde se encuentra $P$. aduncun, tales como la temperatura, precipitación, altitud, intensidad y dirección del viento, luz, entre otros, juegan un papel importante en la presencia de diferentes tipos de compuestos químicos (Mesquita et al. 2005, Oliveira et al. 2006). Para Guerrini et al. (2009), estas diferencias en composición pudieron ser causadas por la errónea identificación botánica o por las diferentes épocas de recolección. Por otro lado, Wadt et al. (2004) observaron que la diversidad genética representada en la colección de germoplasma de la pimienta larga (Piper hispidinervum C. DC.) de Embrapa Acre fue alto, y las especies $P$. aduncum y $P$. hispidinervum eran diferentes genéticamente. Resultados contrarios fueron presentados por Nunes et al. (2007), quienes utilizaron el análisis de cariotipo con estas dos especies, también pertenecientes a la colección de germoplasma en Embrapa Acre, demostrando no haber una diferencia genética entre las dos. Concluyendo que se trata de una sola especie, siendo $P$. hispidinervum una variedad de $P$. aduncum, con una distribución geográfica restringida.

Debido a que esta especie no invierte en los tejidos de lignificación, probablemente su defensa es principalmente química (Marinho 2008), teniendo en cuenta el alto número de estructuras secretoras y de metabolitos secretados, que también pueden estar relacionados con las diversas actividades terapéuticas que se le atribuyen.

\section{CONCLUSIONES}

El mesófilo de la lámina de Piper aduncum es dorsiventral con capas subcelulares en ambas superficies y con estomas hipoestomáticos tetracíticos y salientes. Una característica importante para identificar las especies es la presencia de idioblastos unicelulares distribuidos sobre las capas subcelulares, epidermis o mesófilo, especialmente tricomas tectores unicelulares y pluricelulares de ápice agudo, y tricomas glandulares globulares y glándulas perladas. Las hojas muestran células con cutícula delgada, estomas salientes y ausencia de depósito de lignina, probablemente está relacionada con el ambiente húmedo en donde esta especie es encontrada.

El contenido de aceite esencial de las hojas de $P$. aduncum fue de $0,63 \%$, con la predominancia de compuestos de terpenos y linalol monoterpeno como mayor compuesto.

\section{AGRADECIMIENTOS}

Nuestros agradecimientos a la Coordinación de Perfeccionamiento del Personal de Nivel Superior del Ministerio de Educación de Brasil (CAPES) y al Consejo Nacional de Desarrollo Científico y Tecnológico de Brasil (CNPq) por las becas concedidas. También se agradece a 
la Dra. Valéria Evangelhista Gomes por la identificación de la especie y a los revisores anónimos por sus valiosos comentarios.

\section{BIBLIOGRAFÍA}

ADAms, R.P. 2001. Identification of essential oil components by gas chromatography/quadrupole mass spectroscopy. Illinois: Allured Publishing Corporation, Carol Stream. 456 pp.

Albiero, A.L.M., A.A.S. Paoli, L.A. de Souza \& K.S.M. Mourão. 2005a. Morfoanatomia dos órgãos vegetativos de Piper crassinervium H.B. \& K. (Piperaceae). Acta Botanica Brasilica 19(2): 305-312.

Albiero, A.L.M., L.A. de SouZA, K.S.M. Mourão, O.J.G. DE Almeida \& W.A.L. Lopes. 2005b. Morfo-anatomia do caule e da folha de Piper gaudichaudianum Kuntze (Piperaceae). Acta Farmaceutica Bonaerense 24(4): 550554.

Albiero, A.L.M., A.A.S. Paoli, L.A. Souza \& K.S.M. Mourão. 2006. Morfoanatomia dos órgãos vegetativos de Piper hispidum Sw. (Piperaceae). Revista Brasileira de Farmacognosia 16(3): 379-391.

Ascensão, L. 2004. Métodos histoquímicos em vegetais. Editora UFV, Viçosa. 22 pp.

Barroso, G.M., E.F. Guimarães, C.L.F. Ichaso, C.G. Costa \& A.L. Peiхото. 1978. Sistemática de Angiospermas do Brasil. Universidade de São Paulo, São Paulo. 443 pp.

Bastos, C.N. \& P.S.B. Albuquerque. 2004. Efeito do óleo de Piper aduncum no controle em pós-colheita de Colletotricum musae em banana. Fitopatologia Brasileira 29(5): 555-557.

Bukatsch, F. 1972. Bemerkungen zur doppelfärbung Astrablau Safranin. Mikrokosmos 61(8): 255.

Castro, E.M. De \& F.J. Pereira. 2007. Anatomia comparada das fanerógamas em diferentes ecossistemas. Editora UFLA/ FAEPE, Lavras. 87 pp.

Cicció-Alberti, J.F. \& C.M. Ballestero. 1997. Constituyentes volátiles de las hojas y espigas de Piper aduncum (Piperaceae) de Costa Rica. Revista de Biología Tropical 45(2): 783-790.

Duarte, M.C.T., G.M. Figueira, A. Sartoratto, V.L.G. Rehder \& C. Delarmelina. 2005. Anti-Candida activity of Brazilian medicinal plants. Journal of Ethnopharmacology 97(2): 305-311.

EsAu, K. 1985. Anatomía vegetal. Omega, Barcelona. 779 pp.

Estrela, J.L.V., M. Fazolin, V. Catani, M.R. Alécio \& M.S. Lima. 2006. Toxicidade de óleos essenciais de Piper aduncum e Piper hispidinervum em Sitophilus zeamais. Pesquisa Agropecuária Brasileira 41(2): 217-222.

FAHN, A. 1990. Plant anatomy. Pergamon Press, Oxford. 588 pp.

FanK-De-Carvalho, S.M. \& D. Graciano-Ribeiro. 2005. Arquitetura, anatomia e histoquímica das folhas de Gomphrena arborescens L.f. (Amaranthaceae). Acta Botânica Brasílica Porto Alegre 19(2): 377-390.

Fazolin, M., J.L.V. Estrela, V. Catani, M.S. de Lima \& M.R AlÉcio. 2005. Toxicidade do óleo de Piper aduncum L. a adultos de Cerotoma tingomarianus Bechyné (Coleoptera: Chrysomelidae). Neotropical Entomology 34(3): 485-489.

Fazolin, M., J.L.V. Estrela, V. Catani, M.R. Alécio \& M.S. DE
Lima. 2007. Propriedade inseticida dos óleos essenciais de Piper hispidinervum C. DC., Piper aduncum L. e Tanaecium nocturnum (Barb. Rodr.) Bur. \& K. Shum sobre Tenebrio molitor L., 1758. Ciência e Agrotecnologia 31(1): 113-120.

Fidalgo, L.M., I.S. Ramos, A.M.M. Alvarez, N.G. Lorente, R.S. Lizama \& J.A. Payrol. 2004. Propiedades antiprotozoarias de aceites esenciales extraídos de plantas cubanas. Revista Cubana de Medicina Tropical 56(3): 230-233.

GAIA, J.M.D. 2004. Similaridade genética de populações naturais de pimenta-de-macaco por análise RAPD. Horticultura Brasileira 22(4): 686-689.

Gottlieb, O.R. \& M.T. Magalhães. 1960. Modified distillation trap. Chemist Analyst 49-114.

Guerrini, A., G. Sacchetti, D. Rossi, G. Paganetto, M. Muzzoli, E. Andreotti, M. Tognolini, M.E. Maldonado \& R. BRUNI. 2009. Bioactivities of Piper aduncum L. and Piper obliquum Ruiz \& Pavon (Piperaceae) essential oils from eastern Ecuador. Environmental Toxicology and Pharmacology 27(1): 39-48.

Gupta, M.P., T.D. Arias \& R.M. Smith. 1983. The composition of the essential oil of Piper aduncum L. from Panama. Revista Latino Americana de Química 14: 35-36.

Jantan, B.I., A.R. Ahmad, A.S. Ahmad \& N.A. Ali. 1994. A comparative study of the essential oils of five Piper species from peninsular Malaysia. Flavour and Fragrance Journal 9: 339-342.

Johansen, D.A. 1940. Plant microtechnique. McGraw-Hill, New York. 523 pp.

Lorenzi, H. \& F.J.A. Matos. 2002. Plantas medicinais no Brasil: nativas e exóticas cultivadas. Instituto Plantarum, Nova Odessa. $512 \mathrm{pp}$

Maia, J.G.S., M.G.S. Zoghbi, E.H.A. Andrade, A.S. Santos, M.H.L. Silva, A.I.R. Luz \& C.N. Bastos. 1998. Constituents of the essential oil of Piper aduncum L. growing wild in the Amazon region. Flavour and Fragrance Journal 13: 269-272.

Marinho, C.R. 2008. Características anatômicas, histoquímica das estruturas secretoras e ontogenia de idioblastos da folha de Pothomorphe umbellata (L.) Miq. (Piperaceae). Dissertação, Universidade Federal de Viçosa, Brasil. 59 pp.

Mesquita, J.M.O., C. Cavaleiro, A.P. Cunha, J.A. Lombardi \& A.B. Oliveira. 2005. Estudo comparativo dos óleos voláteis de algumas espécies de Piperaceae. Revista Brasileira de Farmacognosia 15(1): 6-12.

Metcalfe, C.R. \& L. Chalk. 1957. Anatomy of dicotyledons. Clarendon Press, Oxford. 1086 pp.

Nascimento, M.E. \& V.C.R. Vilhena Potiguara. 1999. Aspéctos anatômicos dos órgãos vegetativos de Piper hispidinervium C. DC. (Piperaceae) e suas estruturas secretoras. Boletim do Museu do Pará Emílio Goeldi 15(1): 39-104.

Navickiene, H.M.D., A. DE A. Morandim, A.C. Alécio, L.O. Regasini, D.C.B. Bergamo, M. Telascrea, A.J. Cavalheiro, M.N. Lopes, V. da S. Bolzani, M. Furlan, M.O.M. Marques, M.C.M. Young \& M.J. Kato. 2006. Composition and antifungal activity of essential oils from Piper aduncum L., Piper arboreum Aub. and Piper tuberculatum Jacq. Química Nova 29(3): 467-470.

NIST-National Institute of Standards and Technology. 1998. PC 
version of the NIST/EPA/NIH mass spectral database. Gaithersgurg: U.S., Department of Commerce.

Nunes, J.D., G.A. Torres, L.C. Davide \& C.C. Salgado. 2007. Citogenética de Piper hispidinervum C. DC. e Piper aduncum L. Pesquisa Agropecuária Brasileira, Brasília 42(7): 1049-1052.

Oliveira, J.C.S. I.J.M. De Dias, C.A.G. da Camara \& M.O.E. Schwartz. 2006. Volatile constituents of the leaf oils of Piper aduncum L. from different regions of Pernambuco (Northeast of Brazil). Journal of Essential Oil Research 18(5): 557-559.

Parmar, V.S., S.C. Jain, K.S. Bisht, R. Jain, P. TANeJa, A. JHa, Om D. Tyagi, A.K. Prasad, J. Wengel, C.E. Olsen \& P.M. Boll. 1997. Phytochemistry of the Genus Piper. Phytochemistry 46(4): 591-673.

Pessini, G.L., A.L.M. Albiero, K.S.M. Mourão, C.V. NaKamura, B.P. Dias Filho \& D.A.G. Cortez. 2003. Análise Farmacognóstica de Piper regnellii (Miq.) C. DC. var. pallescens (C. DC.) Yunck. Aspéctos botânicos e enfoque físico-químico preliminar. Latin American Journal of Pharmacy 22(3): 209-216.

Pino, J.A., R., Marbot, A. Bello \& A. Urquiola. 2004. Essential oils of Piper peltata (L.) Miq. and Piper aduncum L. Journal of Essential Oil Research 16: 124-126.

Rali, T., S.W. Wossa, D.N. Leach \& P.G. Waterman. 2007. Volatile chemical constituents of Piper aduncum L and Piper gibbilimbum C. DC. (Piperaceae). Molecules 12(3): 389-394.

Reis, A. \& A. Mariot. 2001. Diversidade natural e aspectos agronômicos de plantas medicinais. En: C.M.O. Simões,
E.P. Chenkel, G. Gosmann, J.C.P. Mello, L.A. Mentz \& P.R. Petrovick (eds.), Farmacognosia da planta ao medicamento. pp. 39-60. Ed. Universidade/UFRGS / Ed. da UFSC, Porto Alegre/Florianópolis, Brasil.

SiLVA, E.M.J. \& S.R. MACHADO. 1999. Estrutura e desenvolvimento dos tricomas secretores em folhas de Piper regnellii (Miq.) C. DC. var. regnellii (Piperaceae). Revista Brasileira de Botânica 22(2): 117-124.

Smith, R.M. \& H. Kassim. 1979. The essential oil of Piper aduncum from Fiji. New Zealand Journal of Science 22: 127-128.

Souza, L.A., I.S. Moscheta \& J.H.G. Oliveira. 2004. Comparative morphology and anatomy of the leaf and stem of Peperomia dahlstedtii C.DC., Ottonia martiana Miq. and Piper diospyrifolium Kunth (Piperaceae). Gayana. Botánica 61(1): 6-17.

Sousa, P.J.C., C.A.L. Barros, J.C.S. Rocha, D.S. Lira, G.M. Monteiro \& J.G.S. Maia. 2008. Avaliação toxicológica do óleo essencial de Piper aduncum L. Revista Brasileira de Farmacognosia 18(2): 217-221

VAn DEN Dool, D.H. \& P.D.J.A. Kratz. 1963. Generalization of the retention index system including linear temperature programmed gas liquid partition chromatography. Journal of Chromatogrography 11: 463-471.

ViannA, W.O. \& G. Akisue. 1997. Caracterização morfológica de Piper aduncum L. Lecta 15(1-2): 11-62.

Wadt, L.H. De O., C. Ehringhaus \& P.Y. Kageyama. 2004. Genetic diversity of "Pimenta Longa" genotypes (Piper spp., Piperaceae) of the Embrapa Acre germplasm collection. Genetics and Molecular Biology 27(1): 74-82.

Recibido: 11.03.11

Aceptado: 06.12.13 